\title{
Knowledge Economy Calls for Anti-Monopoly Law Regulation Innovation
}

\author{
Liang-hui Li \\ Zhongyuan University of Technology, Zhengzhou, Henan, China
}

\begin{abstract}
For a long time, monopoly problem attracted more than economics, law, sociology and other scholars in the field of research. In view of the natural monopoly and economic ties, the antitrust laws in the era of knowledge economy, adapt to the society, science and technology and the change of the economic need and take the initiative to change become inevitable. Early antitrust law regulation mode on "monopoly or not" judgment of swing is not qualitative, choose the mode of regulation "ambiguity" status, for scholars to look at the top of the era and the future, to explore the law of antitrust regulation mode. In the study of anti monopoly law, absorbing the essence from the new institutional economics will be a development direction for the regulation of anti monopoly law reform ideas. Ultimately promoting the development of knowledge economy society.
\end{abstract}

Keywords - anti-monopoly law, knowledge economy, intellectual property rights

\section{知识经济呼唤反垄断法规制理念的革新}

\author{
李亮辉 \\ 中原工学院, 河南, 郑州, 中国
}

摘 要 长期以来, 垄断问题吸引了经济学、法学、社会学等多领域学者们的研究目光。鉴于垄断与经济学的天然联系, 反垄断法 在知识经济时代，顺应社会、科技和经济变化之需要而主动变革成为必然。早期反垄断法规制模式下对“垄断与否”判断的摇摆不定性、 对规制方式选择的“模棱两可”状态, 要求学者们站在时代之巅、远眺未来、探究规律。主动创新反垄断规制方式, 从新制度经济学中 吸收精华应用于法学研究将是反垄断法规制理念革新的一个发展方向, 以此助力知识经济社会发展。

关键词 反垄断法,知识经济,知识产权

1. 引言

作为“经济宪法”、“自由企业大宪章”的反垄断法自其诞 生之日，便肩负着规范和维持良性市场经济运行的艰巨使 命。这一使命描绘出了市场、企业、与适当国家干预之间 和谐共存的有序蓝图。美国《谢尔曼法》号称现代意义反 垄断法鼻祖, 其从颁布至今已逾 120 载, 期间它跨越国界, 超越国体及政体形式在世界各国落地生根。据美国联邦贸 易委员会统计, 至今世界上已有 100 多个国家制定了反垄 断法。[1]反垄断法得以广泛实施的原因之一是共同的经济 学理论基础及共通的市场经济体制背景; 二是世界各国对 反垄断法在防止市场竞争不充分、防范非法限制竞争、维 持自由公平之竞争秩序、保护社会经济活力之永续四个方
面基本使命的高度肯定。故此, 从某种程度来说, 现代各 国维护和发展市场经济不可或缺的法律基石之一就是反垄 断法。

\section{2. 工业时代反垄断法基本原理}

被誉为“美国最有影响的反垄断法学者”的赫伯特.霍温 坎普(Herbert Hovenkamp)教授认为, 任何一个反托拉斯政 策都需要一套完整的经济理论为基础[2]。反垄断法从某种 意义上讲, 自其产生便与经济学天然地融合在了一起, 以 至于任何一名学者若要对反垄断法进行深入研究, 都必然 要涉及经济学的相关理论。纵观反垄断法百余年发展历史, 十九世纪末, 工业化飞速发展导致资本和经济力量迅速高

教育部人文社会科学研究基金项目(编号：14YJC820027) 
度集中。垄断集团开始在经济领域大作侵犯消费者利益, 在政治领域肆意侵蚀民主政治制度, 尤为重要的是它近乎 摧毁了社会进步的核心动力——市场竞争机制。在此背景 下, 自十九世纪中叶至二十世纪初, 美国爆发了多次大规 模的反托拉斯运动, 基于社会变革的需要, 产生了美国现 代意义的反垄断法律制度。

早期的反垄断法律制度是以经济自由主义和经济民主 主义 ${ }^{\mathrm{I}}$ 为经济学理论基础, 由此衍生出一系列基本概念, 并 在此基础上形成相应的法律制度, 诸如: 垄断的涵义、竞 争的涵义、反垄断法规制的对象及适用除外、反垄断法规 制制度、相关市场等等。由于早期反垄断法构建于经济自 由主义与经济民主主义之上, 故其本质是从社会经济整体 利益出发, 通过国家公权利干预经济, 实现经济自由、民 主发展的法律。也即国家通过前期对市场竞争主体一一企 业行为进行有效监督和对企业滥用垄断力量的严格禁止, 来实现平衡经济结构、有序发展经济的目标。国家干预的 最终目标是保护市场主体间的自由竞争和肯定自由、效率、 公平、正义等社会价值。可以说, 早期反垄断法规制的主 要对象是垄断企业, 适用的范围多局限在一国的国内市场。

考察各国反垄断法律制度, 令人惊讶的是均未给垄断 下一个精确的法学定义。但无论大陆法系或英美法系国家, 其对垄断本质的认定却殊途同归。垄断就经济学而言, 是 指与竞争相对立的一种经济结构, 通常将垄断者表述为一 个为了卖出较大量的产品必须降低价格的卖者。萨缪尔森 认为“单一的出售者完全控制某一企业 (这个单一的出售者 称为“垄断者’......)。单一的出售者是它所在产业里的唯一 生产者, 同时没有任何一个企业能够生产出接近的替代 品。”[3]曼昆认为“垄断是一种没有相近替代品的产品的唯 一卖者的企业。”[4]而经济学所指无竞争的市场状态并非法 律意义上的垄断概念。法学意义的垄断是滥用没有竞争的 市场状态来实施排斥竞争的行为; 此外, 对于虽无此状态 但欲实现此类状态的市场行为。其一般特征表现为四个方 面: 第一, 垄断既指垄断的状态, 更指追求、获得、维持、 巩固垄断的行为。第二, 垄断必须是实质上造成在一定市 场范围内限制和排斥竞争。第三, 垄断既包括垄断主体的 个别行为也包括联合行为。第四, 垄断是一种违法行为。 [5]基于垄断的上述共性认识, 各国反垄断立法创造了丰富 具体的垄断控制制度和针对垄断的规范标准。但无论是以

${ }^{\mathrm{I}}$ 自由竞争理论的奠基人是英国古典经济学家亚当·斯密。要点是 提倡市场机制, 反对人为干涉经济, 并提出了 “垄断弊害论” 。 经济民主主义理论以经济机会均等和经济平等为主要内容。在美 国罗斯福总统 1938 年提交议会的反垄断咨文中最早明确提出使 反垄断法实现经济民主作用的设想。
规范垄断状态为特征的日本的结构性垄断控制制度, 或是 以规范垄断化为特点的美国的准结构性垄断控制制度, 或 是以规范垄断力滥用为特征的德国的行为性垄断控制制 度，其共同特征是拥有“市场支配地位”。因此，早期反垄 断立法对垄断的认定直于当时经济学知识发展水平, 仅以 现实经济生活中可触及的具体市场为视角, 也即以相关产 品、时间和地域这三个维度的市场为考察范围, 考量企业 是否具备独定产品价格、主导产品产量和销售等方面的完 全控制力, 同时是否随之实施了破坏自由竞争秩序的行为。 这种界定, 是在对市场量化指标进行综合评定的基础上, 判断企业是否达到市场支配地位, 看到的仅仅是垄断的表 面现象, 是对垄断的一种可量化的现实主义的分析路径。

\section{3. 知识经济时代社会经济新变迁}

人类社会现已全面进入知识经济时代, 这个时代是以 知识作为社会的基石, 是一个完全不同于农业和工业经济 的全新经济社会。20 世纪 90 年代, 著名未来学学者阿尔 温. 托夫勒在《权力的转移》一书中提出: “我们时代最重要 的经济发展, 是创造财富的新系统, 这个系统不再以体力 为基础, 而是基于脑力”[6]。知识经济时代, 人类社会生活 中最敏感的国内或国际政治经济问题不是财富或资源该如 何分配, 而是生产财富的知识产权的分配问题。在所有人 类领域出现的全球性权力之争的核心, 就是如何控制知识。 这场发端于 20 世纪 80 年代、席卷全球的“知识风暴”正是新 技术革命的演进和升华, 其中最典型和具影响力的理应是 网络技术和基因技术。

新技术衍生出了新的知识财产, 从而出现了许多新型 知识产权, 诸如信息网络传播权、数据库作者权、域名、 手机软件以及非物质文化遗产等等; 另一方面, “颠覆性技 术” “直接成就了各种经济创新模式, 诸如跨境电子商务、 网络金融服务等等。此外, 在新技术渗透使用中, 出现了 将汽车行业与互联网结合起来的车联网, 将信息技术 (IT) 和生物技术 (BT) 结合起来的生物信息产业, 将信息技术 和能源技术 (ET) 结合起来的能源互联网业, 呈现出各个 行业向融合式跨界式发展, 导致行业间的界限越来越模糊, 而互联网更使市场呈全球化发展趋势。2015 年 3 月 5 日, 在北京召开的第十二届全国人民代表大会第三次会议上, 中国国家总理李克强首次在政府工作报告中提出了 “互联 网+”行动计划, 标志着中国从政府层面启动了以互联网为 基础设施和实现工具的经济发展新形态。面对新型知识产

\footnotetext{
匹 “颠覆性技术” 最早由美国哈佛商学院著名教授克莱顿. 克里斯 坦森(Clayton M. Christensen)提出, 其颠覆性创新理论旨在描述新 技术 (革命性变革) 对公司存在的影响。
} 
权、新兴跨界产业、新盛全球市场的迅速发展, 反垄断法 实施中对“相关市场”的认定将更趋复杂。相应地, 实务案 件处理中对垄断企业“市场支配地位”判定必将更加艰难。

\section{4. 反垄断法规制理念革新的基本方向}

众所周知, “作为科技、经济与法律结合产物的知识产 权制度是一种在实质上解决 “知识'作为资源归属问题的利 益激励和调节机制”[7]。从这一角度来说, 21 世纪的知识 革命强烈呼唤着相关知识产权法律制度的现代化。随着知 识产权制度的现代化以及持续更新的知识产品利用方式的 市场化和全球化, 更迫切要求知识产权法律制度和反垄断 法律制度突破原有框架, 朝着新型化方向发展。

\section{1 相关经济学理论基础的演变}

早在 20 世纪 30 年代, 新古典经济学家们还在努力研 究其价格理论时, 作为新制度经济学鼻祖的科斯教授发表 了一篇题为“企业的性质”的短文。科斯凭借此文和 23 年后 发表的另一篇文章《社会成本的问题》成为 1991 年诺贝尔 经济学奖得主。进入 20 世纪 60 年代后, 以科斯教授的产 权和交易费用理论为基石, 新制度经济学蓬勃发展并形成 了涵盖产权理论、交易费用理论、制度变迁理论、公共选 择理论、宪政经济学和法与经济学等诸多领域的研究范畴 [8]。新制度经济学理论, 同时在经济学和法学两大学科领 域, 产生了巨大的影响。

\section{2 反垄断领域及反垄断法的发展趋势}

经济学理论的深入发展和创新, 使得法学领域的变革 成为必然。尤其是依赖经济学理论构建的反垄断法, 因其 使命是对市场竞争秩序进行规制、与经济联系密切, 并且 在知识经济背景下, 各种新型垄断现象单纯依靠传统反垄 断法律制度进行规制已显艰难。近三十年来, IT 产业的垄 断、侵权案件层出不穷, 信息产业发展到今天, 在某种程 度上似乎成了“法庭上的 IT 业”。1997 年美国司法部起诉微 软公司案、2003 年美国思科系统公司起诉中国华为技术有 限公司案以及 2013 年奇虎诉腾讯滥用市场支配地位案, 都 与知识产权有关, 都是高科技行业、涉及互联网。虽从表 面看是涉及知识产权的纠纷, 但透过现象看本质, 以上案 件共同昭示出知识经济时代, 在反垄断领域及反垄断法的 未来发展趋势: 特殊技术的拥有者更易于占据市场支配地 位从而达至垄断, 而被知识产权合法保护的特殊技术所有 者在一定条件下理应成为反垄断法的规制对象。

\section{3 反垄断法规制理念革新的方向}

知识经济时代, 反垄断与知识产权的冲突与协调已成
为各国立法者与执法者共同关注的焦点。过去将知识产权 一概划入反垄断适用除外的做法, 在知识经济社会中显得 武断、显失公平。此外, 在互联网+时代, 依靠传统的单纯 从表面数字和可触及的实体市场角度来对“相关市场”进行 量化的做法，难以客观、公平地判定企业是否占据“市场支 配地位”、是否构成“垄断”。那么, 政府在对相关企业和产 业进行反垄断管理和规制时, 到底该以何种标准进行“垄断 与否”的判定, 又应以何种规制方式对垄断企业进行惩处, 才能更好地维护市场竞争秩序又不扼杀高科技企业的创新 实力呢? 前述新制度经济学的兴起, 为反垄断法理论发展 提供了一套与工业经济时代反垄断法理全然不同的新经济 学方法论。在反垄断法研究中, 从新制度经济学中吸收精 华应用于法学研究将是反垄断法规制理念革新的一个发展 方向。

\section{5. 结语}

知识经济时代的到来, 一方面在各国社会经济、政治、 文化、教育等领域发生着改变; 另一方面社会关系、社会 活动内容的变革也挑战着旧有的社会机制和社会秩序。直 于立法的滞后性, 知识经济时代反垄断问题的新特点正直 接挑战着诞生于工业经济时代的传统反垄断法律制度。反 垄断法律制度顺应知识经济时代新变化, 主动革新已成为 人类社会历史发展的必然需求, 并必将强力推进知识经济 时代的蓬勃发展。

\section{参考文献(References)}

[1] See Ky P. Ewing, Jr. ,Competition Rules for the 21st Century: Principles from America's Experience, Alphen aan den Rijn: Kluwer Law International, 2006, p. 1.

[2] Herbert eindhoven kemp, Xu Guangyao, "Federal antitrust policy: competition law and practice," Beijing: law press, 2009.

[3] Paul samuelson, William nordhaus, "Economics", Beijing: huaxia press, 2002, p.127.

[4] Mankun, "Economics principle", Beijing: Beijing University press, 1999,p.316.

[5] Wang Riyi, "Theory of antitrust general theory and basic system", Chinese law, February 1997.

[6] Mr Alwan, "Toffler. The transfer of rights", Beijing: the central committee of the communist party of China party school press, 1991.

[7] Wu handong, Li Ruideng, "30 years research intellectual property law in China", Journal of local research, May2010.

[8] Sheng hong, "The modern institutional economics", Beijing: China publishing house, 2009. 